literacy of the population in the Russian Federation, its connection with concepts of economic behavior. Implementation of measures that increase the financial literacy of the population in modern conditions in the Russian Federation takes place in several areas. One of these areas is the formation of financially competent behavior models. The article addresses the issue of the effectiveness of currently implemented measures aimed at the formation of such behavioral models not only based on objective indicators, but also taking into account the views of participants in financial processes and institutions. The work reflects the results of a comprehensive case study, which includes an expert survey of 150 representatives of financial, state and educational institutions from 30 regions of the Russian Federation and a mass survey of Russian youth, including 4,500 students and 850 schoolchildren.

Keywords: financial literacy, financially competent behavior, strategy for improving financial literacy, behavioral attitudes, criteria for increasing financial literacy

ВАГАПОВА Фирдаус Габдуллазяновна - кандидат филологических наук, доцент; старший научный сотрудник Ресурсного центра по развитию исламского и исламоведческого образования Института международных отношений Казанского (Приволжсккого) федерального университета (420008, Россия, Республика Татарстан, г. Казань, ул. Пушкина, 1/55, корп. 312)

ВАГАПОВ Ренат Наильевич - кандидат политических наук; советник отдела профилактики экстремизма на религиозной почве Управления мониторинга в сфере межнациональных и межкконфессиональных отношений ФАДН России

УСТИНКИН Сергей Васильевич - доктор исторических наук, профессор; декан факультета международных отношений, экономики и управления, профессор кафедры международных отношений и политологии Нижегородского государственного лингвистического университета им. Н.А. Добролюбова (603155, Россия, г. Нижний Новгород, ул. Минина, 31а); директор Приволжского филиала Федерального научно-исследовательского социологического иентра РАН (603000, Россия, г. Нижний Новгород, пер. Холодный, 4; sv.ustinkin@gmail.com)

\title{
НЕКОММЕРЧЕСКАЯ ОРГАНИЗАЦИЯ (НКО) В СОЦИАЛЬНО-ПОЛИТИЧЕСКИХ ПРОЦЕССАХ СОВРЕМЕННОЙ РОССИИ: ТЕОРЕТИЧЕСКИЙ АСПЕКТ
}

Аннотация. Современное состояние гражданского общества России представляет особый интерес и актуальность при рассмотрении возможности гражданского участия общественных объединений в политических процессах современной России. Для общественности становятся приоритетным объектом внимания вопросы выстраивания отношений органов власти и структур гражданского общества в различных областях политики, участия некоммерческих организаций в разработке и претворении в жизнь политического курса государства. Необходимо рассматривать НКО как полноценных акторов социальной политики, которые выполняют функции в сфере социальной заботы и защиты, аналогичные государственным.

Ключевые слова: неправительственные некоммерческие организации, социально-политический процесс, гражданское общество России

$\mathrm{H}$ а рубеже тысячелетий процесс активизации гражданской деятельности дал толчок возникновению и развитию гражданского общества.

Гражданское общество часто рассматривает «третий сектор» как действующий независимо от двух других секторов общества - государства и рынка, но в то же время играющий роль посредника между ними. Этот третий сектор должен состоять из организаций, которые имеют формальную структуру и незави- 
симое управление, платят налоги и обеспечивают работой значительную часть населения, но при этом носят некоммерческий характер. Однако в России в спорах, касающихся взаимоотношений этих трех секторов, максимальное внимание уделяется, безусловно, отношениям между государством и гражданским обществом [Шведов 2013].

Состояние российского гражданского общества на данный момент представляет особый интерес при рассмотрении возможности гражданского участия общественных объединений в политических процессах современной России. Для общественности становятся приоритетным объектом внимания вопросы: как выстраиваются отношения органов власти и структур гражданского общества в различных областях политики, каково участие неправительственных некоммерческих организаций в разработке и претворении в жизнь политического курса государства.

Мировая история наглядно показывает возрастающее значение ассоциаций граждан, оказывающих серьезное воздействие не только на внутреннюю политику государства, но и на внешнюю политику, сферу международных отношений. Масштабы влияния общественных организаций, которые часто определяются как неправительственные организации, на состояние международных политических дел расширяются, и, что особенно важно, их усилия плодотворно развертываются в сфере международно-правового обеспечения прав и свобод человека. Некоторые международно-правовые акты, документы Совещания по безопасности и сотрудничеству в Европе, например Парижская хартия для новой Европы (1990), Всемирная конференция по правам человека (1993 г.), отмечают особую роль НКО в защите всех прав человека, поощрении общественности в гуманитарной деятельности на национальном, региональном и международном уровнях, подчеркивают важность диалога и сотрудничества между правительствами и неправительственными организациями в вопросах международно-правового и социально-политического регулирования гражданского общества [Юрьев 2012].

Закон Российской Федерации «О некоммерческих организациях» в качестве НКО признает такую организацию, которая не имеет основной целью своей деятельности извлечение прибыли для себя и не распределяет полученную прибыль между участниками ${ }^{1}$. Существует множество определений, обозначающих некоммерческие неправительственные организации: НКО (некоммерческие организации), НПО (неправительственные организации), ОГО (организации гражданского общества).

Понятие «неправительственные организации» (НПО), как правило, чаще используют, когда подразумевают деятельность организаций, действующих в пространстве между государством и рынком (то есть, они не являются ни административными, ни коммерческими). Это, например, группы по интересам, правозащитные группы и гражданские ассоциации [Дорошева 2002]. Такую категорию организаций называют еще организациями гражданского общества, чтобы иметь возможность характеризовать различные типы «организаций, осуществляющих независимую деятельность». Официально НПО и ОГО могут быть зарегистрированы как ассоциации, некоммерческие организации, некоммерческие партнерства, фонды, движения, учреждения.

Главной целью некоммерческих организаций является общественная польза и защита интересов граждан, прямой функцией - решение социальных задач и обеспечение взаимодействия внутри социума.

1 Закон Российской Федерации «О некоммерческих организациях» от 12.01.1996 № 7-Ф3. Доступ: http://www.consultant.ru/document/cons_doc_LAW_8824/ (проверено 08.01.2020). 
Активность НКО показывает, что в управленческом процессе они становятся важными участниками социально-политической жизни страны, и это обстоятельство диктует необходимость более пристального внимания и глубокого знания их природы, особенностей функционирования, чтобы объективно оценивать их участие в развитии политико-управленческого процесса. Кроме того, значение НКО необходимо учитывать и при выработке практических рекомендаций, чтобы вывести управление на более высокий уровень эффективности. В связи с этим можно констатировать, что изменения в сфере управления и публичной политики происходят потому, что участниками процесса выработки и реализации публичной политики, помимо государства, становятся институты гражданского общества и структуры бизнеса.

Принимая во внимание тот факт, что государство делегирует некоммерческим организациям некоторые функции поставщиков социальных благ и услуг различным слоям населения, необходимо рассматривать НКО как полноценных акторов социальной политики. Таким образом, происходит модификация традиционных управленческих функций - от государства в сторону НКО. Как отмечают исследователи, сейчас наблюдается тенденция возрастания политического значения групп интересов, в число которых входят и НКО, для формирования новой системы функционального представительства, участниками которой, «представляющими интересы третьей стороны (первая и вторая государственный сектор и бизнес), наряду с профсоюзами, нередко оттесняя их на второй план, стали НКО» [Перегудов 2004: 16; Шведов 2013].

В посланиях Федеральному собранию Российской Федерации ${ }^{1}$ президент России заявлял, что политические процессы невозможно представить без участия неправительственных объединений, а именно без учета их мнений и позиций. В частности, отмечается рост числа общественных организаций, возрастающая численность их членов-добровольцев, а также усиление государственной поддержки социально важных для государства проектов НКО.

В связи с этим актуализируется проблема значимости и роли неправительственных объединений как в обществе, так и в политическом процессе. НКО образуются по принципу самоуправления (и самоорганизации) граждан с конкретной целью. Предполагая наличие стратегии как ключевого элемента деятельности и принципа самоорганизации, НКО можно отнести к стратегическому субъекту [Лепский 2015; Райков 2006].

Принято при стратегическом анализе НКО выделять внешние и внутренние факторы. Отчасти внешние факторы определяются реальной ситуацией в стране, регионе, городе и политической традицией. Внутренние стратегические факторы требуют анализа различных типов НКО с тем, чтобы сформулировать некие универсальные данные.

Говоря о формах участия в социально-политическом процессе общественных объединений, можно отметить, что наивысшей степенью участия, при которой можно оказывать влияние, являются делегирование некоммерческим организациям со стороны государства некоторых полномочий социальной сферы и гражданского контроля. При таком положении гражданские структуры представлены в органах, где осуществляется процесс принятия решений и контроля за их исполнением.

Исходя из либеральной традиции, в которой гражданское общество выступает как «контролер» государства, НКО являются институтами, связывающими частную и общественную (государственную) сферы. Но далеко не во всех регио-

\footnotetext{
${ }^{1}$ Справочник официальных сайтов органов власти Российской Федерации. Доступ: http:// priroda.inc.ru/blog/spravki.html (проверено 08.01.2020).
} 
нах России возможно существование такой нормативной модели гражданского участия 1 . Это свидетельствует о том, что внешним стратегическим фактором, влияющим на деятельность НКО, в первую очередь является состояние законодательной базы, включая региональные законодательные акты в отношении общественного участия граждан, предоставления информации органами государственной власти о деятельности и т.д.

Легитимационная модель предполагает иную роль НКО, а именно как института, придающего легитимность действиям органов государственной власти. То есть, НКО как бы допущены к процессу принятия социально-политических решений, но на совещательной основе в форме неправительственных организаций, таких как общественные палаты, экспертные советы, общественные группы и пр. В данном случае внимание сконцентрировано на таких факторах, как сложившаяся политическая культура, общественные ожидания и ожидания органов власти по отношению к НКО. Здесь возможен следующий сценарий развития событий. НКО становятся «мостиком», соединяющим и транслирующим интересы и потребности общества, бизнеса и государства [Вагапов, Вагапова, Устинкин 2014а]. Ведь НКО служат выражению интересов и идей не только граждан, но и бизнес-структур (союзы и ассоциации предпринимателей), научных объединений, разрабатывающих и продвигающих инновационный продукт, а также общественных сил со сформулированными политическими идеями.

Владимир Путин, выступая в ноябре 2017 г. в Москве на форуме «Сообщество», заявил, что НКО должны стать надежным партнером государства ${ }^{2}$. России, уверен президент, нужны тысячи некоммерческих организаций, которые станут партнерами государства в социальной сфере. Необходимо объединение усилий, единство в ответственности за страну.

НКО стремятся проводить мониторинг ситуации на местах, а также осуществлять экспертизу принимаемых властями решений. Через анализ эффективности решения общественных проблем реализуется идея гражданского контроля, т.е. использования инструментальной модели, подразумевающей активное участие НКО на «выходе» (модель взаимодействия политической системы и окружающей среды Д. Истона). По мнению Д. Истона, у политической системы есть вход, на который извне поступают импульсы-требования или импульсы-поддержка. На выходе системы - политические решения, на основе которых осуществляются политические действия [Истон 1997].

Важно понять, как реализуется активность НКО, а именно какова степень их участия в принятии решений органами государственной власти, каким образом осуществляется демонстрация поддержки их имплементации либо протест. Таким образом, внутренний фактор как вовлеченность организации третьего сектора рассматривается как фактор влияния в стратегическом планировании. НКО могут проявлять себя как пассивный участник управленческого процесса в сообществе (принятие директивы «сверху»), но могут и выступать как активный субъект социально-экономического и политического действия (добровольное принятие ответственности за оказание услуги или предоставление «общественного блага» и его эффективность, т.е. наибольший эффект при минимальных издержках).

Значимая роль НКО в социально-политической сфере состоит в их уникальном знании практических особенностей и специфики населения и условий

\footnotetext{
1 Горный М.Б. Общественное участие некоммерческих организаций. Доступ: http://www. civisbook.ru/files/File/Gornyi_uchastie.pdf (проверено 08.01.2020).

2 Путин: НКО должны стать надежным партнером государства. Доступ: https://www.tvc.ru/ news/show/id/126865 (проверено 08.01.2020).
} 
проживания граждан. То есть, именно неправительственные, некоммерческие организации могут провести анализ реальной ситуации и оценить уровень прогресса в переходе к информационному обществу и электронной демократии.

В такой ситуации могут оказаться полезными для поиска консенсуса и выбора эффективного способа влияния НКО на внешние факторы (имеется в виду как государство, так и бизнес) известные информационные технологии поддержки проведения стратегических совещаний, обеспечивающие ускорение достижения согласия относительно целей и путей действий людей в малых, средних и больших группах. Сложность задачи обратно пропорциональна времени на ее решение, и требуется некое информационное пространство, где представлены полезные данные, прошедшие «информационный фильтр» по содержанию различных аспектов и рисков, включая политические, экономические, экологические и т.д. В таком пространстве осуществляется мониторинг, прогнозирование, принятие решений, процесс их имплементации и контроля. Стратегические совещания для малых и средних групп людей эффективны в локальных ситуационных центрах, что вполне реализуемо на базе действующих аналитических некоммерческих структур, так называемых аналитических центров. Ввиду того, что аналитические центры распространяют результаты своей интеллектуальной деятельности на ту аудиторию, на чье мнение они стремятся повлиять, целесообразно обратиться к структурам, которые хотят повлиять на лиц, ответственных за принятие политического решения, а именно к центрам публичной политики (ЦПП). ЦПП представляют собой организации, которые непосредственно участвуют в сфере публичной политики и активно инициируют процесс обсуждения значимой проблемы, зафиксированной общественностью. Кроме того, ЦПП создают аналитический продукт для публикации и распространения. В данном случае предполагается связь с определенным сектором общества, интеллектуальная независимость, выражаемая в создании аналитического продукта (исследование потребностей граждан, информационный анализ, реализация общественного/социального проекта).

Формы участия и воздействия на объект влияния, будь то общественность, власть или бизнес, в сети Интернет заслуживает отдельного внимания. Путем создания определенного информационного поля и направления определенной информации группам можно пробудить их интерес, способствовать стремлению присоединиться к организации и взаимодействовать с другими субъектами [Пушкарева 2014].

Некоммерческие организации, которых в России десятки тысяч, казалось бы, первыми должны использовать Интернет в своей деятельности. Тот факт, что этого не произошло, косвенно свидетельствует о слабости структур гражданского общества в России. Сайты, созданные НКО, в лучшем случае выполняют функцию «визитных карточек», где, как правило, представлена какая-либо информация о деятельности организации и минимальные контактные данные.

Основными формами участия, а соответственно и возможностями влияния современных НКО являются письменные обращения в органы власти, привлечение СМИ, участие в законодательных инициативах, проведение общественной экспертизы, инициативы по организации маршей протеста и демонстраций, лоббирование через аппарат органов власти, личные связи с лицами, ответственными за принятие решения. Сложно говорить об эффективности тех или иных форм - все зависит от представителей центральной власти в регионах, от региональных лидеров и лидера каждой отдельной организации. Если говорить о новых возможностях, предоставляемых телекоммуникационными системами, то они не реализуются в полной мере. Учитывая слова Р. Даля, что «институты должны быть обогащены новыми методами, способствующими раз- 
витию гражданского самосознания, участию граждан в политической жизни, получению информации, обсуждению проблем» [Даль 2003], можно предположить, что в скором будущем именно технологические факторы будут определяющими в политическом процессе.

Таким образом, при постановке стратегического содержания учитываются интересы не только населения (общества и представляющих его объединений), но и государства, и частного сектора (бизнеса). Поэтому, на наш взгляд, важно, каким образом НКО может оказывать давление на органы власти (исполнительную и законодательную) и бизнес.

Рост числа создаваемых НКО и повышение активности общественности привлекает в ряды НКО руководителей администрации для более глубокого осмысления ситуации в регионе [Вагапов, Вагапова, Устинкин 2014б]. Различные институциональные структуры и политические инициативы в области законодательства выступают в качестве весомых характеристик влияния НКО на процесс принятия политических решений. Так, развитие идеи о социальнополитической ответственности способствует созданию условий, в которых организации третьего сектора имеют больше шансов быть услышанными. С другой стороны, активные НКО не только в общественно-политическом поле, но и в информационном намерены сотрудничать с местной или региональной администрацией и согласны получать поддержку от бизнеса. В последнее время очень актуальной становится идея взаимодействия бизнеса и власти (развитие механизма государственно-частного партнерства), а также социальной ответственности бизнеса. Это способствует активизации НКО как потенциального индикатора проблемных сфер и в то же время продвижению и прохождению представителей некоммерческих структур в ряды региональной политической элиты страны для урегулирования запросов и согласования интересов общественности. Здесь речь не идет о возможностях для представителей НКО попасть в ряды государственных служащих категории «А» через волеизъявление граждан (хотя это своего рода способ проникнуть в структуры власти, где готовится решение). Но такая процедура требует определенной стратегической договоренности и нивелирования противоречий всех участников процесса борьбы за политическое влияние. Выгода такого положения заключается в статусе представителя НКО.

Можем констатировать, что создание системы ситуационных и аналитических центров, центров публичной политики способствует решению внутренних задач НКО и консолидации гражданского общества. Ситуационные центры предполагают своего рода «действие по ситуации», т.е. управление нового формата: когда фактор времени, отпущенного на решение задач, становится первой угрозой извне, а сложность и комплексность решений повышаются. Рекрутирование в круг лиц, принимающих политические решения, или элиты можно рассматривать как одну из внешних возможностей влияния НКО, хотя такой способ требует привлечения значительных ресурсов.

Президент РФ Владимир Путин отметил, что правительство приняло необходимые решения для предоставления преференций социально ориентированным НКО, доказавшим эффективность своей работы, и рассчитывает, что в ближайшее время будут приняты необходимые поправки к законодательству, позволяющие реализовать практический механизм получения особого правового статуса социально ориентированными НКО с 1 января 2017 г. ${ }^{1}$ Не случайно 2018 г. был объявлен в России годом волонтера и добровольца. В пра-

\footnotetext{
1 Путин надеется, что социальные НКО смогут получить особый статус с 1 января. - РИА Новости. 03.11.2016. Доступ: https://ria.ru/20161103/1480623859.html (проверено 08.01.2020).
} 
вительстве отмечают особую роль НКО в исполнении майских указов президента ${ }^{1}$. Президент РФ Владимир Путин подписал указ о создании автономной некоммерческой организации «Россия - страна возможностей» ${ }^{2}$. Расширяется программа президентских грантов для $\mathrm{HKO}^{3}$. Президент также отмечает, что гражданское общество и власть заинтересованы в том, чтобы активный приход НКО в социальную сферу вел к повышению ее качества.

В заключение отметим, что актуальность статуса общественных объединений определяется множеством факторов, диктующих необходимость фундаментальных социально-политических реформ в России, перехода от прежней жестко централизованной системы руководства экономическими, социальнополитическими и иными процессами к системе, открывающей широкие возможности для общественного самоуправления, саморегуляции и самодеятельности граждан РФ. Можно уверенно констатировать, что, несмотря на относительно незначительный по времени период своего существования в России, НКО прочно заняли свою нишу в социально-политической организации современного государственного устройства страны.

Хотя на данном этапе российские неправительственные некоммерческие организации уже сложились как самостоятельный общественный институт политической организации российского общества с собственной идеологией, стандартами деятельности, системой символических и культурных признаков, однако, на наш взгляд, есть некоторые опасения, что часть социально-политически ориентированных НКО могут стать для власти «карманными» организациями, если сама власть инициирует их создание, финансирует и назначает их руководителей. Мы стоим на позиции, что третий сектор формирует потенциал взаимного доверия и взаимопомощи, который является социально-политическим капиталом в обществе. Значение НКО возрастает всегда, когда государство переживает потрясения и кризисы и когда от каждого гражданина зачастую зависит и его судьба, и судьба страны.

\section{Список литературы}

Вагапов Р.Н., Вагапова Ф.Г., Устинкин С.В. 2014а. Роль исламских организаиий в политическом процессе современной России: учебное пособие. Н. Новгород: НГЛУ. 117 с.

Вагапов Р.Н., Вагапова Ф.Г., Устинкин С.В. 2014б. Потенциал организаций мусульманского духовенства в развитии и регулировании социально-политических процессов России: монография. Н. Новгород: НГЛУ. 106 с.

Даль Р. 2003. Одемократии (пер. с англ. под ред. М.В. Ильина). М.: РОССПЭН. $576 \mathrm{c}$.

Дорошева Н.M. 2002. Все, чтовыхотели знатьо некоммерческомсекторе, нобоялись спросить: пособие для журналистов. М.: САF. 75 с. Доступ: https://docplayer. $\mathrm{ru} / 106843$-Natalya-dorosheva-vse-chto-vy-hoteli-znat-o-nekommercheskomsektore-no-boyalis-sprosit-posobie-dlya-zhurnalistov.html\#show_full_text (проверено 08.01.2020).

Истон Д. 1997. Политическая система (1953), Концептуальная структура для политического анализа (1965), Системный анализ политической жизни (1965).

\footnotetext{
1 В Правительстве отмечают особую роль НКО в исполнении майских указов Президента. - Комсомольская правда. 01.08.2018. Доступ: https://www.kazan.kp.ru/daily/26862/3905316/ (проверено 08.01.2020).

2 Владимир Путин подписал указ о создании НКО «Россия - страна возможностей». Доступ: https://www.kommersant.ru/doc/3636404 (проверено 08.01.2020).

3 Путин надеется, что социальные НКО смогут получить особый статус с 1 января.
} 
- Антология мировой политической мысли: в 5 т. М.: Мысль. Т. ІІ. С. 630-642. Доступ: http://read.virmk.ru/i/Iston.htm (проверено 08.01.2020).

Лепский В.Е. 2015. Эволюция представлений об управлении (методологический и философский анализ). М.: Когито-Центр. 107 с.

Перегудов С. 2004. Группы интересов в условиях перехода к информационному обществу. - Мировая экономика и межкународные отношения. № 6. С. 13-20.

Пушкарева Г.В. 2014. Политический менеджмент: учебник и практикум для академического бакалавриата. М.: Юрайт. 365 с.

Райков А.Н. 2006. Самоорганизация в информационном обществе. Информационные и телекоммуникационные технологии. № 1. С. 8-12.

Шведов Г. 2013. Гражданское общество в России: Заметки практика. Гражданское общество в России: 1000 статей. НП «Редакция журнала ПОЛИС (Политические исследования)»; ИС РАН. Материалы научной электронной библиотеки «Гражданское общество в России». М.: ИС РАН.

Юрьев С.С. Правовой статус общественных объединений: автореф. дис. ... к.ю.н. М. 1995. 26 с. Доступ: http://law.edu.ru/book/book.asp?bookID=1257575 (проверено 22.01.2020).

VAGAPOVA Firdaus Gabdullazyanovna, Cand.Sci. (Philol.), Associate Professor, Senior Researcher of the Resource Center for the Development of Islamic Education and Islamic Studies, Institute of International Relations, Kazan (Volga Region) Federal University (app. 312, 1/55 Pushkina St, Kazan, Republic of Tatarstan, Russia, 420008)

VAGAPOV Renat Nail'evich, Cand.Sci. (Pol.Sci), Advisor to the Department for the Prevention of Extremism at Religious Grounds, Office for Monitoring Interethnic and Interfaith Relations of the Federal Agency for Nationalities (FADN) of Russia

USTINKIN Sergei Vasil'evich, Dr.Sci. (Hist.), Professor; Dean of Faculty of International Relations, Economics and Management, Professor of the Chair of International Relations and Political Science, Dobroljubov State Linguistics University of Nizhny Novgorod (31a Minina St, Nizhny Novgorod, Russia, 603155); Director of Volga Branch of the Federal Center of Theoretical and Applied Sociology, Russian Academy of Sciences (4 Holodny Lane, Nizhny Novgorod, Russia, 603000; sv.ustinkin@gmail.com)

\title{
NON-PROFIT ORGANIZATION IN SOCIAL AND POLITICAL PROCESSES OF MODERN RUSSIA: THE THEORETICAL ASPECT
}

\begin{abstract}
The current state of Russian civil society is of particular interest and relevance when considering the possibility of civil participation of public associations in the political processes of modern Russia. The issues of building relations between the authorities and civil society structures in various areas of policy, and the participation of non-profit organizations in the development and implementation of the political course of the state are becoming a priority for the public. It is necessary to consider the activities of non-profit organizations as full-fledged actors of social policy, which perform functions in the field of social care and protection similar to those of the state.

Keywords: non-governmental non-profit organizations, socio-political process, civil society of Russia
\end{abstract}

